\title{
Hydrometeorological and vegetation indices for the drought monitoring system in Tuscany Region, Italy
}

\author{
F. Caparrini ${ }^{1,2}$ and F. Manzella ${ }^{1}$ \\ ${ }^{1}$ Centro Funzionale Regione Toscana, Pisa, Italy \\ ${ }^{2}$ Eumechanos, Firenze, Italy
}

Received: 16 January 2008 - Revised: 19 May 2008 - Accepted: 11 March 2009 - Published: 16 March 2009

\begin{abstract}
We present here the first experiments for an integrated system that is under development for drought monitoring and water resources assessment in Tuscany Region in central Italy. The system is based on the cross-evaluation of the Standardized Precipitation Index (SPI), Vegetation Indices from remote sensing (from MODIS and SEVIRIMSG), and outputs from the distributed hydrological model MOBIDIC, that is used in real-time for water balance evaluation and hydrological forecast in the major basins of Tuscany.

Furthermore, a telemetric network of aquifer levels is near completion in the region, and data from nearly 50 stations are already available in real-time.

Preliminary estimates of drought indices over Tuscany in the first eight months of 2007 are shown, and pathway for further studies on the correlation between patterns of crop water stress, precipitation deficit and groundwater conditions is discussed.
\end{abstract}

\section{Introduction}

It is known that drought is a complex phenomenon whose impacts have different time scales. Although a drought is always the consequence of a natural reduction in the amount of precipitation over an extended period of time (usually a season or more) its severity depends on the duration, season of occurrence, spatial extent of the affected area and, ultimately, on the impacts it causes to human activities, agriculture and environment.

For these reasons, a unique definition of drought does not exist (Wilhite and Glantz, 1985; Wilhite, 1993) and the onset and conclusion of a specific event is difficult to determine. A drought can happen in every climate, with varying intensities and impacts, and is not limited to arid areas where scarcity of precipitation is a permanent climatic condition.

Compared to other natural hazards, in a sense, drought is more difficult to monitor since it is a slow phenomenon (some authors say "creeping", Tannehill, 1947) and its impacts can be underestimated until they reach peak intensities. On the other hand, the mitigation of damages caused by drought require an adequate water resources planning that can be efficiently accomplished only if routine monitoring has been carried on.

Monitoring drought means to simultaneously evaluate all the possible causes and impacts on the soil-vegetation system, i.e. (a) computing if the cumulated precipitation over a relevant period of time can be considered insufficient with respect to some expected value, (b) estimating if and when such rainfall scarcity provokes reduction in streamflow and lowering of groundwater levels, (c) assessing if soil moisture conditions are sufficient to guarantee an adequate water supply to crops and vegetation. These effects are strictly correlated and to some extent consequential: however, interactions are complex and can be difficult to predict. Time scale of analysis has therefore to be multiple in order to capture all the different effects.

Spatial issues are also essential: contrary to other hazards, drought impacts are spread over large geographical areas and their intensity and severity may vary depending on many local environmental factors. The availability of dense telemetric networks and the advent of new measuring techniques from remote sensing represent an invaluable tool for drought monitoring at regional scale.

In this paper we present the first experiments for the development of a drought monitoring system at Centro Funzionale Regione Toscana (CF Toscana), the hydrometeorological monitoring agency of Tuscany Region in Italy. 


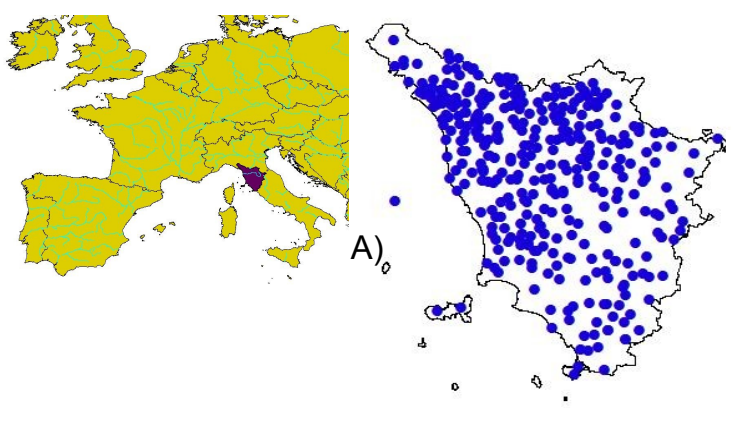

B)
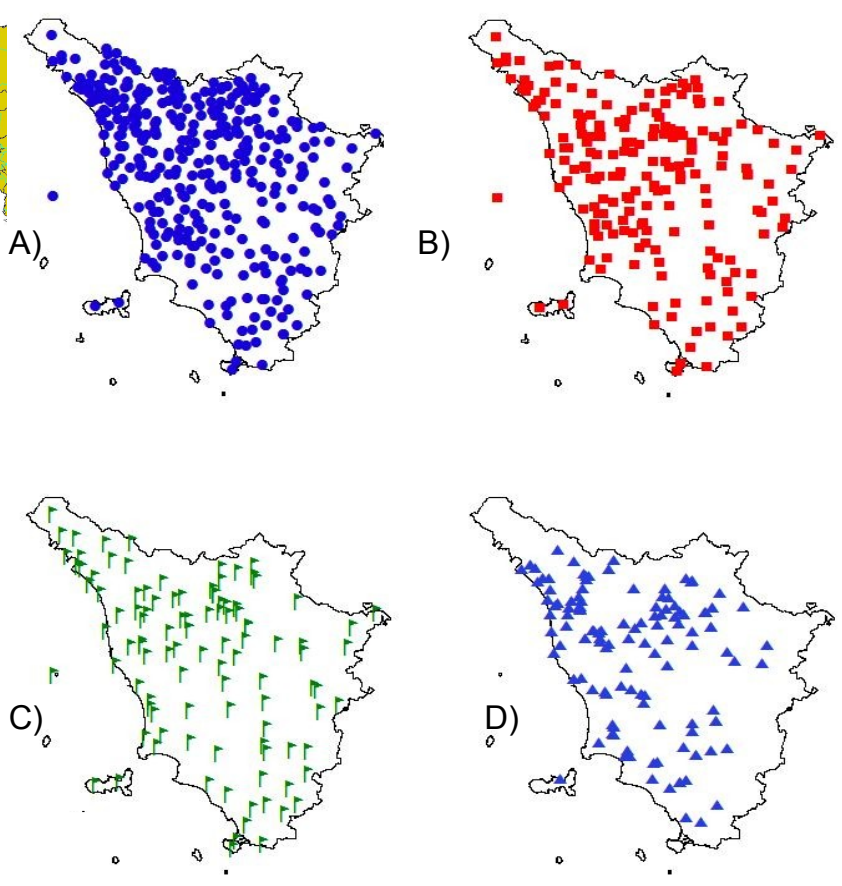

Fig. 1. Location of Tuscany Region (upper left) and regional hydrometeorological network (as of 2007): (A) raingauges, (B) termometers, (C) anemometers; (D) hydrometers.

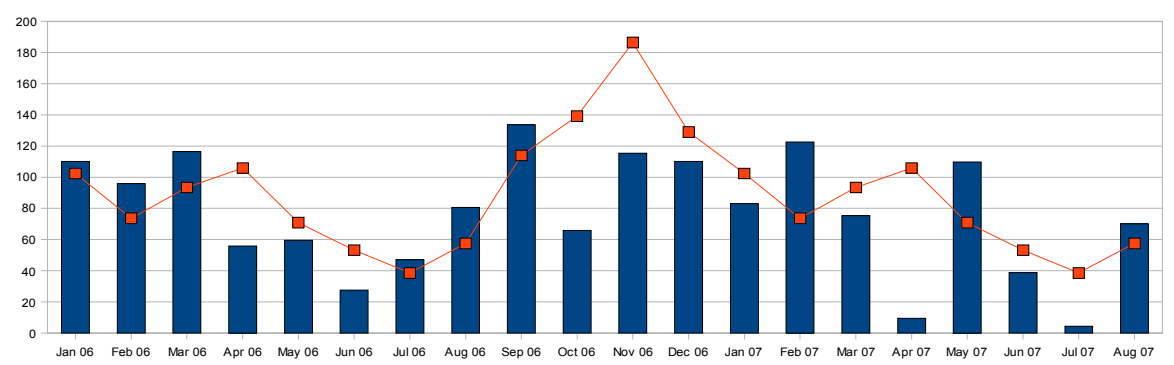

Fig. 2. Bars of cumulated monthly precipitation (average of all stations in Tuscany, mm) from January 2006 to August 2007 . Red solid line is the average precipitation in the period 1996-2006.

\section{The hydrometeorological monitoring system in Tuscany Region}

Tuscany Region covers an area of approximately $20000 \mathrm{~km}^{2}$ in central Italy and is bounded by the Apennines mountains on the North, with maximum elevation reaching $1300 \mathrm{~m}$ a.s.l. Main land cover types are oliveyards, vineyards, and forests in the mountain areas.

A fairly dense telemetric hydrometeorological network is available in the region, run and maintained by Centro Funzionale Regione Toscana, including 359 rain gauges, 191 thermometers, 101 anemometers and 128 hydrometers (Fig. 1).

A network of real time measurements of groundwater level is also under development: 45, phreatimeteres are already operational and, on completion, the network will be composed of nearly 100 instruments placed in the major aquifer bodies of the region, becoming one of the most remarkable real-time monitoring systems of groundwater conditions in Italy.

In addition to the great amount of observation data, the hydrometeorological system of Tuscany can benefit of estimates and prediction of hydrological variables from the model MOBIDIC (MOdello di Bilancio Idrologico DIstribuito e Continuo - Distributed and Continuous Model for the Hydrological Balance, Campo et al., 2006). MOBIDIC is a distributed model that has been implemented in real time mode for the major basins in the region (Arno, Serchio, Ombrone Grossetano, Cecina, Magra, Tevere). The model is fed with data from the hydrometeorological network with $15^{\prime}$ 

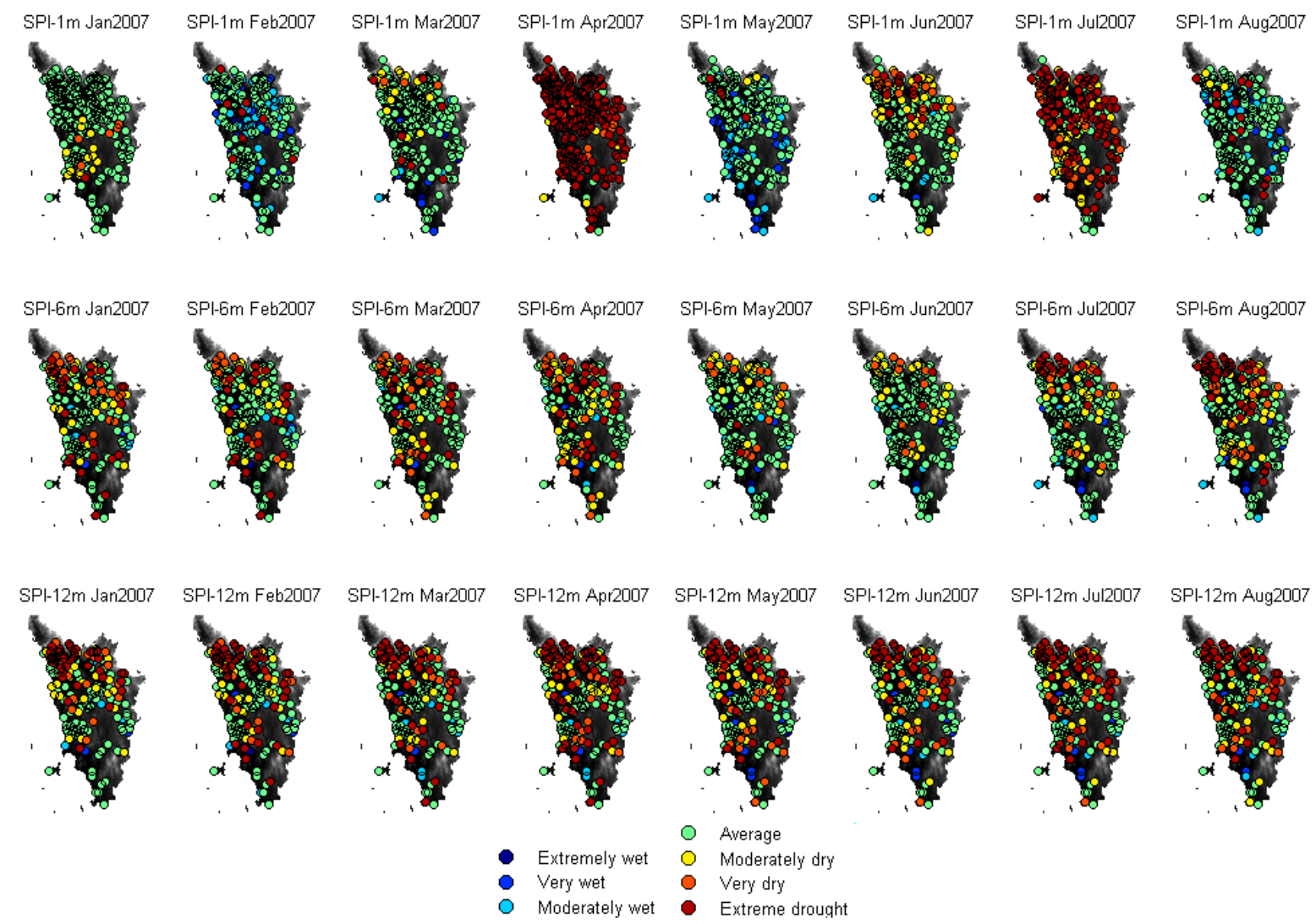

Fig. 3. Standardized Precipitation Index (SPI) for the first eight months of 2007: top row) 1-month time scale; central row) 6-months; lower row) 12-months.

time step and quantitative precipitation forecast (QPF) from four different meteorological Limited Area Models.

The outputs of MOBIDIC are estimated and predicted soil water content (in "large" and "small" pores), hydrological and energy balance components (evapotranspiration, soil temperature) and discharge in each branch of the river network, including minor branches.

\section{Drought indices in 2007}

Local authorities in Tuscany region have dedicated a great attention to water resources management and drought risk in 2007. Winter 2006, in fact, has been relatively dry, with precipitation below average for many stations especially in the "traditionally" wetter months (November). The first months of 2007 have been variable with an exceptionally dry April, when several rain gauges have measured zero precipitation for the whole month. Averages of monthly precipitation recorded by the instruments of CF Toscana are shown in Fig. 2. Naturally, in some cases spatial behaviour has been inhomogeneous, with some stations recording precipitation above their average and other severely below average.
The overall situation has urged the CF Toscana to start experiments and studies to set up an operational drought monitoring system, following international examples like the US Drought Monitor (www.drought.unl.edu).

Main components of such system will be: (1) meteorological indices from the statistical analysis of recorded rainfall data; (2) Vegetation Indices from remote sensing; (3) Soil moisture conditions from MOBIDIC model; (4) Streamflow Indices and comparison with long-term flow duration curves; (5) Groundwater conditions from the phreatimetric network.

Ultimately, overall drought severity indices that integrate all the informations above will be developed.

In this paper we present the first estimations of meteorological and Vegetation Indices over Tuscany for the first 8 months of 2007.

\section{Standardised Precipitation Index (SPI)}

Meteorological drought indices describe how the observed precipitation in a certain period differs from "normal" (longterm) conditions. Percent of normal is the simplest way to express such deviation from average conditions. However, it has been widely observed that cumulated precipitation does 


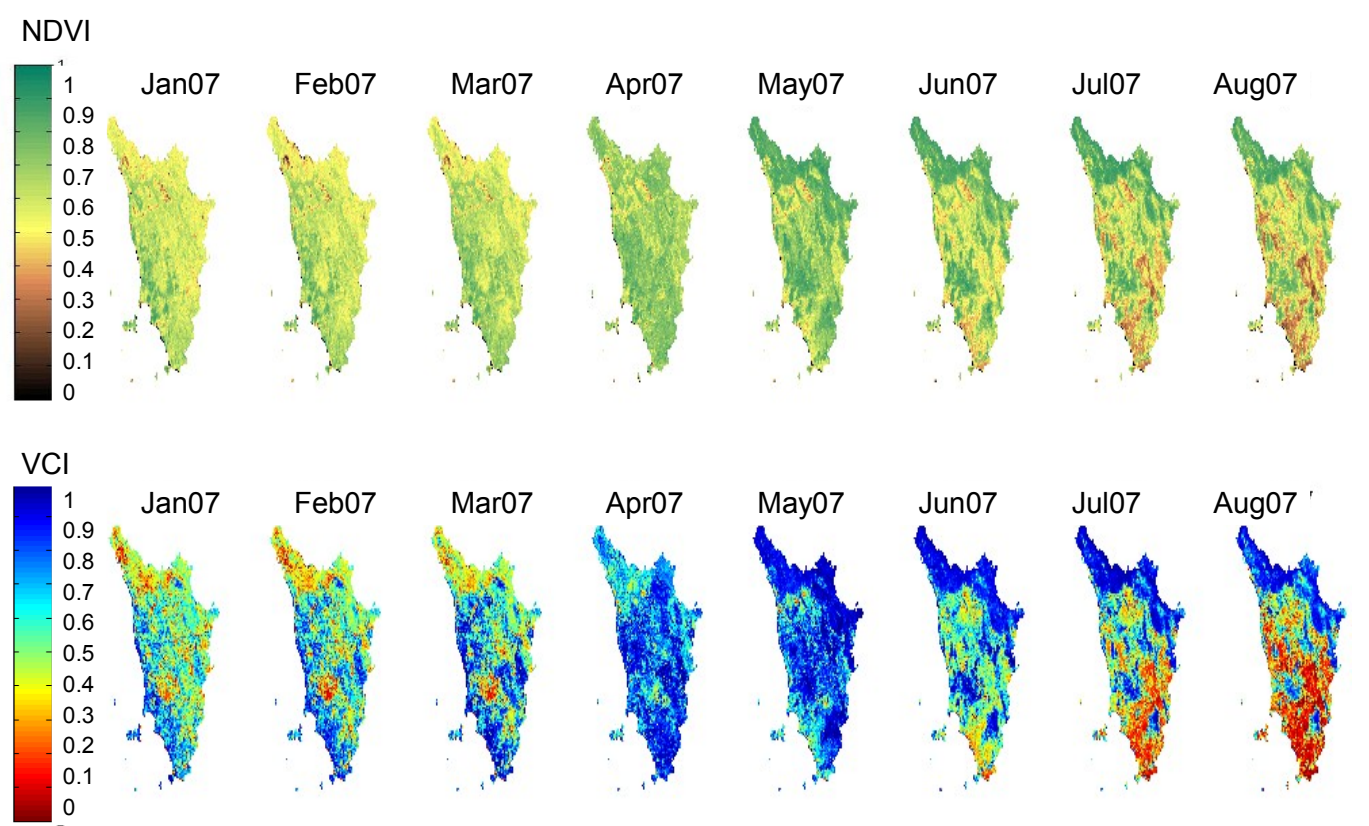

Fig. 4. Vegetation conditions in Tuscany in the period January-August 2007 from satellite-based indices. Top: Normalised Difference Vegetation Index (NDVI); Bottom: Vegetation Condition Index (VCI).

not follow a normal distribution: therefore, considering the percent of normal may lead to errors in estimating the actual severity of precipitation deficits. The Standardised Precipitation Index (SPI), introduced by McKee (McKee et al., 1995; Bordi et al., 2001) is a more robust index since it is calculated by fitting the time series of cumulated precipitation with a more suitable distribution. Usually a Gamma function is used:

$f(x)=\frac{x^{\alpha-1} \cdot e^{-\frac{x}{\beta}}}{\beta^{\alpha} \cdot \Gamma(\alpha)} ; \Gamma(\alpha)=\int_{0}^{\infty} t^{\alpha-1} \cdot e^{-t} d t$

The Gamma probability is then re-transformed back into a normal CDF to obtain SPI.

Positive SPI values indicate greater than median precipitation, while negative values indicate less than median precipitation. Because the SPI is normalized, wetter and drier climates can be represented in the same way, and wet periods can also be monitored using the SPI. The classification proposed by McKee (Table 1) is usually adopted to tag wet/dry conditions.

SPI is usually calculated on different time scales, considering for each calculation step the cumulated precipitation in a given period (e.g. 1, 6, 12, 24 months..). Each SPI index contains peculiar information on phenomena that have different time scales (e.g. 1 month time scale can be irrelevant for impacts on streamflow and groundwater while it might affect types of crops that need a constant provision of water, while 12 months can be a relevant scale for groundwater resources but not yet for perennial vegetation, and so on).
Figure 3 shows the SPI indices over Tuscany in 2007. Indices have been calculated only for stations where values for 2007 can be compared with a historical time series at least 30 -years long. For recent rain gauge stations that do not have such a long historical record, a corresponding "historic" station can be used, but only if it was placed in the same location and with the same shading and microclimatic conditions. Since only a perfunctory validation on input data was performed in this stage of the work, results must be considered preliminary and experimental.

The SPI indices shown in Fig. 3 are calculated on the basis of the cumulated precipitation in the previous 1,6 , and 12 months. At shorter time scale, it can be noted that April and July 2007 have been exceptionally dry on the whole regional territory, and 1-month SPI index for most stations falls below -2 . Precipitation events in other months immediately bring back the 1-month SPI value to more normal conditions (see May, August 2007).

When considering longer time scales, different spatial patterns of wet/dry (in terms of SPI) conditions appear and other considerations arise. In particular, when considering a 12 month time window, that incorporates also the effects of the relatively dry winter of 2006, it is shown that critical SPI values persist, especially in North-West Tuscany and in some southern coastal areas. 


\section{Remote sensing of vegetation conditions}

Water stress monitoring in crops and vegetation is one of the major aspects that need to be considered for agricultural and environmental reasons. The impact of a prolonged precipitation deficit depends on plant type and its phenological cycle, and is also affected by other climatic factors such as air and soil temperature, humidity, solar radiation. Therefore, the analysis of meteorological indices such as SPI alone is not sufficient to monitor and analyse the conditions of crops and vegetation. A severe precipitation deficit may be irrelevant for a certain type of vegetation while a slight deficit may have serious impacts on other types, especially if lack of precipitation occurs in critical phases of growth process.

Spectral Indices from remote sensing have become in the last decade one of the major tools for monitoring vegetation conditions (McVicar and Jupp, 1998; Kogan, 1990). Such indices are usually calculated exploiting the fact that healthy vegetation has a fairly different behaviour in terms of reflection of electromagnetic radiation in the wavelength of red and near-infrared. For example, the Normalised Difference Vegetation Index (NDVI) is the normalised difference, calculated on a pixel by pixel basis, between energy reflected in the near infrared (NIR) and red bands:

$\mathrm{NDVI}=\frac{\mathrm{NIR}-\mathrm{Red}}{\mathrm{NIR}+\mathrm{Red}}$

NDVI values close to 1 indicate very dense vegetation, while values near 0 indicate bare soil or very sparse vegetation. Negative values of NDVI usually correspond to water bodies or urban areas. Top panel of Fig. 4 shows the NDVI values obtained from the MODIS (Moderate Resolution Imaging Spectroradiometer) over Tuscany region for the first eight months of 2007. Woodlands in the Appenines area have high values in the summer and lower values in the winter months due to deciduous vegetation. Croplands, oliveyards and vineyards in the central part of region exhibit a seasonal cycle with very low values in summer 2007.

Low values of NDVI indicates bare and arid areas but NDVI by itself cannot be considered a drought index since the concept of drought implies an extreme condition and a deviation from normal status. In terms of vegetation dynamics, a drought is an event that hampers the normal vegetation growth.

In order to capture this effect, and to compare drought conditions in areas with different land cover, NDVI has to be scaled with regard to some measurement of potential vegetation growth for the given crop type and climatic condition. Kogan (Kogan, 1995; Liu and Kogan, 1996) introduced the Vegetation Condition Index (VCI). For a given period i (e.g. a given month) $\mathrm{VCI}$ is calculated as:

$\mathrm{VCI}_{\mathrm{i}}=\frac{\mathrm{NDVI}_{\mathrm{i}}-\mathrm{NDVI}_{\text {min }}}{\mathrm{NDVI}_{\max }-\mathrm{NDVI}_{\min }}$
Table 1. Classification of dry and wet conditions according to SPI index (after McKee et al., 1995).

\begin{tabular}{rr}
\hline SPI Values & Condition \\
\hline $\mathrm{SPI} \geq 2$ & extremely wet \\
$1.5 \leq \mathrm{SPI}<2$ & very wet \\
$1 \leq \mathrm{SPI}<1.5$ & moderately wet \\
$-1 \leq \mathrm{SPI}<+1$ & near normal \\
$-1.5 \leq \mathrm{SPI}<-1$ & moderately dry \\
$-2 \leq \mathrm{SPI}<-1.5$ & severely dry \\
$\mathrm{SPI} \leq-2$ & extremely dry \\
\hline
\end{tabular}

where $\mathrm{NDVI}_{i}$ is the Normalised Difference Vegetation Index for the analysed period and $\mathrm{NDVI}_{\max }, \mathrm{NDVI}_{\min }$ are the absolute extreme values of NDVI calculated from a dataset of 'historical' NDVI images of the area. VCI was developed in order to assess changes in the NDVI signal over time due to weather conditions only, minimising the effects of local conditions and topography.

VCI can be calculated only if reliable records of satellite images for a sufficient number of years are available; this opens some issues since recent remote sensing instruments (e.g. MODIS itself, or Meteosat Second Generation) have been operational for less than a decade. Some 'historic' instruments such as the AVHRR (still operational) have longer time series but comparison between different sensors is difficult due to inconsistent instrument specifics like viewing angles and methods for atmospheric correction. Cloud or snow presence is also a major issue. The availability of qualitychecked postprocessed datasets of NDVIs is therefore fundamental.

Lower panel of Fig. 4 show the VCI index for Tuscany in January-August 2007 (from MODIS NDVI). Values close to 0 indicate alleged water stress. It is shown that cropland areas, especially in South Tuscany, exhibit very low VCI values, while the woodlands in the mountain areas have low VCI in the first months of the year while values increase to "healthy" vegetation conditions in the following months. As said before, the shortness of time series of MODIS images (only 7 years were used for the evaluation of minimum and maximum NDVI values) may seriously influence the estimation.

\section{Concluding remarks and further work}

The analysis of drought indices over Tuscany in the first eight months of 2007 has shown that neither the SPI nor the vegetation indices alone can fully describe the severity of drought 
conditions. Intensity, severity and spatial patterns of drought impacts depend on many factors that must be evaluated from different perspectives.

The data network and modelling capabilities at $\mathrm{CF}$ Toscana allow to develop multi-index drought classification schemes, incorporating also the effects on soil moisture, surface water bodies, natural and artificial reservoirs.

Further work will be necessary to finalize the system and to try to introduce some kind of prediction capabilities. In spite of the seemingly straightforward consequentiality of drought impacts (low precipitation leads to low soil moisture that leads to low water availability for plants, etc.), interactions are complex and different time scales play a fundamental role.

Drought forecasting can be attempted following different approaches, either using statistical auto-regressive models such as ARIMA/SARIMA, and/or through the integration of seasonal weather predictions into an adapted version of the hydrological model MOBIDIC. The latter approach implies feeding the MOBIDIC model with long-term precipitation forecast from seasonal models and computing the expected moisture conditions in soil, vegetation and groundwater layers.

Once operational and improved, the drought monitoring system will serve as a very valuable decision support tool for water resources management and evaluation in Tuscany region, and can be used for many agricultural and environmental applications.

Acknowledgements. The authors thank their colleagues at Centro Funzionale Regione Toscana in Pisa and Florence for their support. MODIS data have been obtained from NASA EOS Data Gateway.

Edited by: G. Roth

Reviewed by: G. Boni

\section{References}

Bordi, I., Frigio, S., Parenti, P., Speranza, A., and Sutera, A.: The analysis of the Standardized Precipitation Index in the Mediterranean areas: regional patterns, Ann. Geofis., 44(5-6), 979-994, 2001.

Campo, L., Caparrini, F., and Castelli F.: Use of Multi-Platform, Multi-Temporal, Remote Sensing Data for Calibration of a Distributed Hydrological Model: An Application in the Arno Basin, Italy, Hydrol. Process., 20, 2693-2712, 2006.

Kogan, F. N.: Remote sensing of weather impacts on vegetation in non-homogeneous areas, Int. J. Remote Sens., 11, 1405-1420, 1990.

Kogan, F. N.: Droughts of the late 1980s in the United States as derive from NOAA polar-orbiting satellite data, B. Am. Meteorol. Soc., 76, 655-668, 1995.

Liu, W. and Kogan, F. N.: Monitoring regional drought using the vegetation condition index, Int. J. Remote Sens., 17, 2761-2782, 1996.

McKee, T. B., Doeksten, N. J., and Kleist, J.: Drought monitoring with different time scales, Proc. 9th Conference on Applied Climatology, Dallas TX, 233-236, 1995.

McVicar, T. R., and Jupp, D. L. B.: The current and potential operational use of remote sensing to aid decisions on drought exceptional circumstances in Australia: a review, Agr. Syst., 57(3), 399-468, 1998.

Tannehill, I. R.: Drought and Its Causes and Effects, Princeton University Press, 597 pp., 1947.

Wilhite, D. A.: Drought assesment, management and planning: theory and case studies, Kluwer Academic Boston, 293 pp., 1993.

Wilhite, D. A. and Glantz, M. H.: Understanding the drought phenomenon: the role of definitions, Water Int., 10, 111-120, 1985. 